\title{
Comments for A New Generation of Rehabilitation Engineers ${ }^{a}$
}

\section{JMFOORT}

Medical Engineering Resource Unit The University of British Columbia clo Shaughnessy Hospital

4500 Oak Street

Vancouver, B.C., Canada V6H 3N1

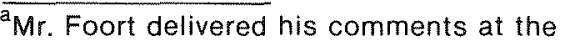
Awards Luncheon, June 20, 1984, during the Second International Conference on Rehabilitation Engineering, which was combined with the RESNA 7th Annual Conference, June 17-22, at Ottawa, Canada.
}

INTRODUCTION - I would like to say at the outset that I am not too satisfied with the term "rehabilitation engineer" because I fear that it will cordon off a function for engineers that may need the skills and capabilities of others. If I accept the classification, rehabilitation engineer, it is to legitimize the engineering function in clinical processes rather than to establish the right of engineers to carry out that function exclusively.

The perspective I have in what is now called rehabilitation engineering spans 33 years. Most of these have been spent in prosthetics of the lower extremities, directed toward design and development coupled to clinical trials. Clinical trials brought me to focus on problems of interfacing equipment with people. This colors my view, naturally, but as one matures one passes from being specifically involved to being generally involved in the problems of rehabilitation.

I offer the following views as a generalist not only in relation to rehabilitation, research, design, and development, but in relation to institutional and professional factors that surround them. First, I would like to tell you a few things I know, then to tell you what I wish I had known when I started in 1951, then what I feel about it now, and finally what I would do if I were to be Methuselah.

\section{A. Starting with what I know:}

1. It is necessary to use teams for solving disability problems. Not that the lone wolf has no place. Such a person often sparks the new Idea, or even the new wave. But conception is a small part of the overall process. Developing concepts into products that clients can use is the demanding and time-consuming task.

Development work requires a team that embraces a variety of skills and that uses positive problem-solving methods to reach well-specified and practical objectives.

"Keystone" problems must be selected for solution. When a keystone problem is solved, many other problems disappear or become easier to solve. An example of a keystone problem is that of interfacing a structure with the body. New approaches currently being worked on may well wipe out the problem of how such interfaces must be shaped. That will liberate us to concentrate on how structures should be matched to tissue qualities to optimize force and movement transfer.

To identify and solve keystone problems requires certain team attributes. In my more recent experiences, I have found a team that includes an old timer with experience, and young members with information, to be especially effective in identifying problems, establishing means for their solution, and carrying them through to solution. 
2. Optimal performance of a team requires cooperation rather than competition. For this to be possible, egocentricity must be subdued and team members must appreciate the capabilities and limitations of their colleagues constructively. When there is a lack within a member, there must either be education to bridge the gap, or supplementation by others. It is worth remembering that we are essentially equal in intelligence, varying most in terms of our experiences and attitudes. The main thing is to appreciate the positive attributes in fellow workers and make it possible for them to receive what they need from you as you derive maximum advantage from their positive attributes. If you know something another does not, if he needs it, make it your responsibility to teach him.

Cooperation rather than competition among teams is similarly desirable. While competition between teams (as exemplified by overlaps or even parallel operations) can be tolerated to a certain level, the range of problems still unsolved remains too wide and the work force too small for this to be extensive.

As matters stand now, the various rehabilitation engineering teams function too much in isolation. There needs to be a division of labour among them, so that the whole range of disability problems can be tackled.

A modular approach to solving problems would be desirable. Between teams, as well as within teams, there must be a will to integrate findings so that the results become used on the broadest front possible, rather than remaining local wonders.

3. Self-evaluation is a prime requirement. This applies to members within teams and to teams as entities. Outputs need to be measured in terms of the value these have for the population being served: Has it been done already by someone else? Is the difference between what you would do and what has been done sufficiently great to warrant the costs involved in doing further design and development work?

When you undertake a project is it cost effective? For example: If you spend a month writing an article, that article has cost about $\$ 3,000$. How many articles worth $\$ 3,000$ have you read?

Your ingredients, as far as outputs are concerned, include your basic knowledge, your temperament as a problem-solver, your capacity to work, the speed with which you work, the skills with which you do it and your level of confidence.

Tensions borne of doubts are to be expected, but they must be realistic. You can deal with some of this if you are prepared to change your opinions. Functioning as your own critic you stand a good chance to maintain the best insights into your own nature and performance and ensure flexibility in your approach. When you are satisfied with your worth and contributions, you will function with greater focus on the problems to be solved.

4. Evaluation of Systems - For as long as I have been involved in rehabilitation engineering, the problem of eval. uating products has been discussed. I have come to this conclusion - that evaluation is best carried out by using what is developing on selected clients. The level of demand which develops is a potent indicator of how the item is valued.

The first stage is to have the actual designer-developer evaluate what he or she has designed on a sufficient scale clinically to reveal whether or not it is a viable solution. But, because the designer-developer is highly motivated to make it work, it is necessary to have a subsequent evaluation of the system by someone further removed.

Educators are obviously suited for the second stage of evaluation in that they need to be familiar with new items and must be in a position to assess them critically for possible entry into the education programs. They will use selected clients within the typical treatment arena. When an idea, device, or tool is sufficiently understood and found to be of proven value, they will let it be known through the educational system on a scale appropriate to the nature of the item and the level of performance of those who will be using it.

Ultimately, a third-stage evaluation in the form of clinicai studies will be needed. Practitioners are the ones to do that. Thereafter, a new item will be entering the stream on the basis of its merit as judged by informed people who are not only competent to make the judgement but who are also in a position to pass on the information. Also, a demand will have been seeded through its step-bystep expo: sure to the relevant people.

The criteria used to evaluate design and development ftems are different from those used to evaluate scientific findings. Tools, techniques, and devices designed and developed for disability management are often destined for use on populations so small that to establish a test sample in itself becomes a major problem. In that case, it is best to rely on engineering testing to specified standards, expert opinion, and user response.

(I have just returned from Europe where great cathedrals, if they had been subjected to scientific evaluation, would in fact never have been built!)

5. A team must be prepared to take risks in the development of new solutions. This is easiest to do in the environment of a successfully operating team. New solutions to old problems often require a daring step. Conservative forces around us may serve to protect us from foolhardy enterprises, and offer us a chance to work through what we would do before we undertake it, but in the last analysis 
a plunge must be taken which leads to new and untested ways. While the conservative impulses will have an inhibiting effect, soon the risky step becomes familiar enough to generate tolerance, and finally, support, as tenability is demonstrated.

Usually a good team will have someone within it who can assume leadership for taking risks.

There is a risklike quality also to the abandonment of untenable ideas. While it takes spirit to make the judgment sometimes, there is no value in plunging on when the moment has passed for a particular idea. There is also no need for embarrassment or shame in the face of good efforts that result in "failure." A true fallure is in fact a result, one which need never be repeated!

New ideas are often fragile. They are similar to the insights of artists and poets. They must be examined sympathetically and with sensitivity. Look, listen, and contribute positively. Then, if the idea must be abandoned, it will have been done on the basis of an appropriate examination from which new directions and values may emerge.

6. Secrecy and a sense of proprietorship need to be absent within teams and between teams. Secrecy isolates and inhibits. Examples of concepts we would probably be better without include copyrights and patents.

Patenting, for example, cannot be successfully done unless we hold back information until the process is completed. That is the first loss. Then, once it is completed, it gives advantages to the holder who extracts a gain. This may not only add a cost in terms of a surcharge, but it may prevent competition, prevent improvements, and even exclude or limit availability of the product on the market. It may introduce a conflict of interest also.

The main objective of our work must surely be to facilitate the integration of the disabled into the community to the level they would choose. If we stand apart from each other, clutching our results for personal, team, or project advantages, we defeat at least a part of this objective.

Publications are for information, and do not represent a staking out of territory. Nor are they in themselves a product. When authorship is shared, it should be on the basis of a genuine contribution by each participant. A good measure of legitimacy is whether or not you can answer any question that might arise from what is in the article.

For the rehabilitation engineer, having made a contribution to the development of a device, tool, technique, or procedure that enters into use must be the ultimate reward.

7. I am amazed by the power of modern technology. The main difference between the original technology of Ford and that of today is that, in mass production as Ford devel- oped it, every object of a kind was the same. Today, it is possible to mass-produce things while making every one different! That distinction makes a particularly cogent case for the use of modern technology in rehabilitation engineering. I advocate that computers, numerically controlled machines, and robots be used in rehabilitation devices and in their design, development, and manufacture. I put to you the possibility that such a committment will also enlarge the scope for disabled people to function as designers, developers, and manufacturers of the things they need.

There is nothing scary about a robot as far as 1 am concerned. If we do not want it or what it does, it is a relic, a piece of junk. On the other hand, the new technology affects the workforce. This reminds me of how, after the last war, we were told of the days of leisure through a shorter work week we would enjoy! As the number of people unemployed increases, I can believe it. This may foster movements against automation and modern technology. That is not so likely in our field, however, because of the difficulties experienced in maintaining a sufficiently large work force and in establishing sufficiently high standards. These are problems that can be solved by the new technologies.

In any event, except through a major catastrophe, what is available for use will be used as long as it reduces the cost in human energy and time. The challenge is to organize these new capabilities to benefit society equitably. As far as their use on behalf of the disabled is concerned, I consider it necessary as our first duty to be sensitive to the potential it has for them. We must not, however, promise more than we can deliver, nor publicize a result that is incomplete.

8. We see in the changing scene how value judgments enter into engineering decisions. Not only does the use of modern technology itself have social consequences, but so do the choices that are made. For example, the very problems selected to be worked on require such judgments. So does the way that we prioritize the range of problems selected to work on. Then, decisions about how the resources to manage them are allocated involve value judgments. Thus, an awareness of the social implications of applying technology is required. When far-reaching effects can be expected from a technological move, it behooves rehabilitation engineers proposing it to look for consensus among colleagues, those affected, and advisors. Then the decision can be made with more confidence.

For this consensus to be possible, there must be networks in place along which information can flow. I believe that such networks need to be developed where they are absent, and to be fostered where they are present. 


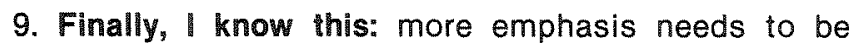
placed on the full range of disability problems. For example, some types of disability receive a disproportionate amount of our time and resources. While what is learned with respect to one population of disabled people may be of relevance to another (as for example, in the fitting and fabrication of the interfaces with which equipment is attached to them or on which they rest), unless this is translated immediately into results for other categories, it is meaningless to them. I am thinking here of what I have learned in prosthetics and how it applies to orthotics, or seating, or other rehabilitation problems.

\section{B. What I wish I had known}

1. The role of the engineer in the clinic is that of problemsolver. Clinicians (and I include orthotists, doctors, pros. thetists, and therapists in this definition) expect quick results when an engineer enters the team.

I wish I had appreciated the need to resist being stampeded into forcing a solution prematurely. Yielding to such pressures can discredit rehabilitation engineering. To solve problems there needs, first, to be a suitable hypothesis. Next, the hypothesis must be tested for its relevance. If it is suitable, the proposed solution must be applied to people for whom it is obviously suited. As experience develops, the limits to its application can be discovered by applying it to people who deviate from the ideal to an ever-increasing degree.

Thus, the purpose of in-house evaluation - the first stage - is to verify suitability of the hypothesis and to identify prescription criteria for its use.

2. Rehabilitation engineers find themselves in clinical settings among people who are versed in what is going on. These people follow a 20-minute cycle to process patients. For the engineer, with a process cycle that can take months or even years, this is threatening. It is imperative that the people associating with engineers understand the different kind of function or role that the engineer brings to the team. The engineer can seldom offer an immediate solution to a particular patient's problem unless, in fact, the problem has already been solved. If it hasn't, the best he can do at that stage is advise. It needs to be understood by the medical people that the engineer sees the patient as an example of the problem, that he must see many such examples before he can begin to appreciate what might be done, and that when he has reached that stage he must formulate his hypothesis and follow through a process of verification until he obtains a solution which has general application.

I wish I had known all that from the beginning, and I wish medical people had known it too.

3. I understood, in time, that the aim of the engineer is to isolate a problem related to a population sufficiently large that it becomes appropriate to spend time and resources developing a solution. Once a general solution is available, it becomes possible to carry out the function of solving the individual's problem in the clinic - if the solution is appropriate.

When the stage is reached when a solution is so clearly appropriate that it can be managed in the clinic, it is no longer appropriate to have the engineer involved except on a consultative or educative basis. I wish I had understood that sooner, and forced transfer of solutions to clinical people as soon as it was appropriate.

Of course, this all requires a competent, receptive clini. cal team.

4. I wish I had known that engineers are likely to be better-informed on problem-solving than most other team members. That is the basis for their training, and their problem-solving function requires of them the ability to see the elements that make up the problem in such a way that relationships between the elements are recog. nized.

I remember a situation in which an orthosis which was obviously worthless for the intended function was given high marks by the patient and the clinical personnel. A consideration of possible reasons led to the conclusion that the orthosis was providing proprioceptive clues that the patient was using to modify the disabling feature. 
Imagine what that means from an engineering point of view! Today, one would think in terms of electrical stimulation or some sort of cluing device, instead of a major appliance that would encumber the client.

5. Besides designing for the disabled population, engineers should aim their solutions even at normals. An obvious example of such a solution is one that prevents disability. Environments can be organized to take into account different levels of human function. High steps encumber the child, the elderly person, and the pregnant woman.
6. Another thing I wish I had known is that the needs of people with the various types of disability have equal value in terms of those needs being met through engineering. It has been very easy for engineers to decide to tackle certain problems (to the exclusion of certain others) on the grounds of the ease with which those problems could be grasped and (perhaps) the glamor associated with their solution. Amputees, for example, have had a very good response in terms of the engineering time and resources applied to their problems in comparison to people with some other types of disability.

I wish that all levels of disability received at least the same level of attention.

\section{My Hunches}

1. A feeling I have always had is that I did not know enough. I feel now that the separation of career from education is wrong; rehabilitators should undergo continuous education. It should be directly tied to what they are attempting to achieve; education-for-education's-sake is not what is being advocated here.

For example, when a person decides that he or she wishes to become a rehabilitation engineer, that person's studies should then be linked directly to something going on clinically. They should be funded adequately. When the studies are finished, a problem will have been solved and the next level of problem-solving which might be appropriate will have been indicated.

Tailoring education to the institutional mold does not always tie in with the needs of humanity. If institutions of higher learning would provide what was needed over a sufficiently long time span to make it continuously relevant, then, in the end, practitioners would be up to date, and they would have a track record of usefulness and continuous exposure to what was current in terms of their technologies and related information. This would also have the effect that what was being learned in practice was being turned back into the universities and technical schools for their development.

2. Organization - I feel that we largely ignore the dem. ocratic principles upon which our institutions are supposed to be based. All sorts of excuses are offered. The drive for power is too prevalent.

In my experience, most people do not like being dictated to. They are quite willing to learn and are quite willing to apply what they have learned. They are also trustworthy. More to be mistrusted are those who mistrust.

it seems to me that if our institutions are to become democratic, there must be a shift away from the vertical structure in organization toward the horizontal one. Rehabilitationists, researchers, should be able to elect their directors and put them out when they are inappropriate. Organization on a functional basis results in leadership coming from the persons with the best ideas; leadership shifts around.

People working in small groups that have humanitarian objectives are in a good position to help to enhance development of a democratic society that has, as its foundation, cooperation rather than competition and ascension to positions of prestige. To achieve this kind of a democratic society, it may be necessary to stand against the idea of inequality of positions and wages. Directing and administering, leading a study group, or running a milling machine are functions related to an operation. That one man is better endowed or differently trained does not signify that he is superior to or worth more than another.

3. Paying one's way - I feel that many of us are extremely fortunate to be engaged in work that is worthwhile, in environments conducive to good human behaviour, and at salaries that do not leave us pinched. We owe something to the human species in return for the care, protection, and trust we are offered.

4. Making it Happen - It is up to us to make things happen. I deplore the attitude of those who complain of lack of funds, red tape, hostile environments, lack of promotions, and the like. If the aim of rehabilitation engineering is to meet the needs of clients for greater functional capacities that will allow them to more nearly reach equality with the population into which they wish to be integrated, then overcoming all impediments to the 
realization of this is part of the rehabilitation engineering function.

For example, medical insurance coverage for all rehabilitation devices would contribute most positively toward establishment of rehabilitation engineering as a natural part of the services. Now, many of us must exercise our role as researchers while the need is not for more information but the integration of what we already know.

Some rehabilitation engineers, understanding the broad perspective of their role, have become educated in psychology, sociology, and other disciplines besides the technologies - so that the stumbling blocks to action can be better understood and perhaps overcome.

5. Paternalism - Disabled people, in my experience, want and need a say in what happens to them. I feel that rehabilitation engineers, standing somewhat apart from other rehabilitation people because of their educational backgrounds and functions, can offer a lot (by way of example) toward meeting this need.

For example: Clients need good information; and, they need a hearing - they need to be included in planning. A client will be impatient for (and disappointed with) a result if not prepared adequately for the process which must follow involvement of the rehabilitation engineer. The client wants a quick and powerful solution. That can seldom be offered, and only information can help the client understand and tolerate the inevitable delay and the possible shortcomings of the solution.

The matter of access to records is only now becoming clarified. I suggest that engineers should organize their information on clients in such a way that it represents good information for the client, too. Also, engineers should make certain that the client understands that these records are accessible to him or to her.

6. Opportunities for Personal Growth - Because reha. bilitation people work in an environment where clients are under the stress of needing, and need to perform in relation to these needs, people working in this field have a very great opportunity for personal growth. Egocentricity has to be outgrown if we are to successfully deal with other people's problems. We have to leave our own needs aside, concentrate on theirs, and as a result, see where our own weaknesses lie as we undertake to meet the demands. Then we can use the awareness of impulses we experience as insights into our own behaviours. From that we can attempt to grow toward more appropriate attitudes.

In the end, one sees a disabled person without sentimentality; sees such a person as just another person, and comes to focus on his problem without forgetting his humanity. Of course, it is not only with regard to the dis. abled persons that our poor attitudes must be overcome through self-awareness. There are many opportunities for cooperation and sharing between workers within a group or among groups. When a number of rehabilitation engineers are working on the same problem, it is necessary to uncover the motives. Does each imagine that he is better equipped to deal with the problem? If one brain is good, surely two are better, and some merger of the effort and knowledge involved should be attempted.

7. Demands from the Other Side - People who are impatient with the degree of progress being made in rehabilitation engineering comment that if we can go to the moon, we ought to be able to solve these problems. No doubt we could do much more with the resources we receive, by planning better, executing our plans with greater care, and cooperating with one another more freely. I think we should be extremely conscientious about wringing the most we can out of our resources and skills. I think also that what we accomplish (rather than what we promise) needs to be the basis for the resources we demand.

On the other hand, we see waste and stupidities around us of the most blatent kind. These tend to reflect differ. ences in opinion about where priorities lie. Two hundred new British amputees, along with other costs, are the price paid for the privilege of flying a particular flag over a set of islands of undetermined name or ownership. As rehabilita. tors, we need to speak out clearly against the anti-rehabilitation atrocities we see carried out or threatened.

8. think engineering holds promise as a means for establishing improved conditions for mankind. Whenl look back over the years of my existence, I must admit to the fact that things in Canada are certainly better now than when I was a child. The death rate among children is down, paraplegics live longer, the general level of medical attention is improved, our communication and transportation networks are marvelous, and life expectancy is high. Engineering has been a factor in this.

Now, we must ensure that the glaring inequalities we still see around us are overcome. Only a will to share will ensure that. The strong are always favoured. A major requirement, which we can face within our field, is to diminish or eliminate those inequalities we see affecting the disabled and fellow workers. The so-called economic "realities" we hear about are a weak excuse for inaction: economics rests on conventions which men make. Those conventions are not immutable. Our productive capacities at all levels are enormous. People who wish to hold onto more than their share stand in the way of reorganization for greater equity.

Continued on page 8 


\section{What I would do if time permitted}

1. Considering it from the applied sciences point of view, I would develop a network of like-thinking people to whom I could turn when I needed to - and for whom I would be a willing resource.

2. I would engage in a course of continuous education designed to give me the broadest possible background from which to define and solve problems. It would be a course of education that linked to immediate projects of direct relevance - and would not necessarily be targeted on an advanced degree.

I would work to get the educational institutions I must deal with to permit me to tailor studies according to my problem-solving needs, free of time and content constraints. I would not confine myself to the technologies, nor to instructions only in institutions of learning. Self-awareness and growth studies would be included.

3. As a researcher-designer, | would work to establish the means by which I could work wherever I felt I could most effectively solve my research-design problems. I feel that it is a mistake to confine people to a single workplace when it might make problem-solving more effective to have them go to a different laboratory, centre, or environment. If such mobility were established, a worker could, by arrangement, go without complications to a source of better information or equipment in relation to the problem to be solved.
4. I would continue to involve myself in small problemsolving groups. If I were in a group that was becoming large, I would try to get it to split up. I would work to maintain members of associated groups in my network, but would recognize the possibility that divergent interests might make this unprofitable.

5. I would try to enter a team that was attached to orthopaedics and rehabilitation. There I would apply the most appropriate technologies for the design and development of systems, tools, devices, and techniques for use in rehabilitation and orthopaedics.

6. Within the constraints of my capabilities, I would assess the field to ensure that my efforts went toward solving problems on the basis of the needs of the clients. The glamour, ease of the work, or personal gain to be realized from it would be secondary 